\title{
Biorremediação de um solo contaminado com antraceno sob diferentes condições físicas e químicas
}

\author{
Bioremediation of a soil contaminated with anthracene under different chemical and \\ physical conditions
}

\author{
Rodrigo Josemar Seminoti Jacques ${ }^{\mathrm{I}}$ Kelly Justin da Silva ${ }^{\mathrm{II}}$ Fátima Menezes Bento ${ }^{\mathrm{III}}$ \\ Flávio Anastácio de Oliveira Camargo ${ }^{\text {IV }}$
}

\section{RESUMO}

$O$ antraceno $e$ os demais hidrocarbonetos aromáticos policíclicos (HAPs) podem ser removidos do solo pela biorremediação, cuja eficiência é limitada se as condições físicas e químicas não forem favoráveis à sobrevivência e à atividade dos microrganismos degradadores. $O$ objetivo do presente estudo foi avaliar a influência do $\mathrm{pH}$, da umidade $e$ da disponibilidade de nitrogênio, de fósforo, de ferro e de enxofre na biorremediação de um solo contaminado com antraceno. Para tanto, amostras de um solo arenoso foram contaminadas em laboratório com $500 \mathrm{mg} \mathrm{kg}^{-1}$ de antraceno $e$ a mineralização desse poluente foi quantificada por respirometria. As maiores mineralizações ocorreram nos tratamentos com as maiores umidades e os $\mathrm{pH}$ avaliados. A adição de $100 \mathrm{~kg} \mathrm{ha}^{-1}$ ou mais de nitrogênio no solo e a redução da relação $C_{H_{A P}}-N$ para valores inferiores a 120:17 diminuíram a mineralização do antraceno. $O$ aumento da disponibilidade do fósforo, do ferro e do enxofre e a presença de amplas relações $C_{H A P}: P$ no solo não influenciaram a mineralização do antraceno. A correção do $\mathrm{pH}$ e o adequado fornecimento de água possibilitaram a biorremediação desse solo em curto período de tempo.

Palavras-chave: biodegradação, hidrocarboneto aromático policíclico, bioestimulação, acidez do solo, umidade do solo.

\section{ABSTRACT}

The anthracene, as well as the others polycyclic aromatic hydrocarbons (PAH), can be removed from the soil by bioremediation, whose efficiency is limited under unfavorable physical and chemical conditions to the survival and activity of the microbial degraders. The objective of this study was to evaluate the influence of $\mathrm{pH}$, water content, and nitrogen,

\begin{abstract}
phosphorus, iron and sulfur concentrations in the bioremediation of a soil contaminated with anthracene. Samples of a sandy soil were contaminated in laboratory with anthracene (500 $\mathrm{mg} \mathrm{kg}^{-1}$ ) and the mineralization was evaluated by respirometry. The highest anthracene mineralization was verified in the soil with the highest water content and $\mathrm{pH}$ value studied. The addition of $100 \mathrm{~kg} \mathrm{ha}^{-1}$ nitrogen in the soil and the consequent reduction of $C_{P A H}-N$ ratio to values lesser than 120:17 reduced anthracene mineralization. The increase of phosphorus iron and sulfur availability and wide $C_{P A H^{-}}-P(120: 1$ to 120:22) ratios in the soil did not influence anthracene mineralization. The $\mathrm{pH}$ correction and appropriate water supply made possible the bioremediation of the soil polluted with anthracene in a short period of time.
\end{abstract}

Key words: biodegradation, polycyclic aromatic hydrocarbon, biostimulation, soil acidity, soil moisture.

\section{INTRODUÇÃO}

$\mathrm{O}$ antraceno $\left(\mathrm{C}_{14} \mathrm{H}_{10}\right)$ é um hidrocarboneto aromático policíclico (HAP) composto por três anéis aromáticos. A geração desse composto, assim como dos demais HAPs, ocorre naturalmente e de forma contínua, pela combustão incompleta da matéria orgânica e da biomassa vegetal (HARITASH \& KAUSHIK, 2009). Porém, a contaminação ambiental está associada à geração antropogênica associada às indústrias petroquímicas, à produção de carvão vegetal, à extração e gaseificação do carvão mineral, e à cadeia de extração, transporte, refino, transformação e

'Departamento de Solos, Universidade Federal de Santa Maria (UFSM), 97105-900, Santa Maria, RS, Brasil. E-mail: rodrigosolos@yahoo.com.br. Autor para correspondência.

IIPrograma de Pós-graduação em Microbiologia Agrícola, Universidade São Paulo (USP), Piracicaba, SP, Brasil.

IIIDepartamento de Microbiologia, Universidade Federal do Rio Grande do Sul (UFRGS), Porto Alegre, RS, Brasil.

${ }^{\text {Iv }}$ Departamento de Solos, UFRGS, Porto Alegre, RS, Brasil. 
utilização do petróleo e de seus derivados (BAMFORTH \& SINGLETON, 2005).

Devido a essas atividades, o solo recebe anualmente grandes quantidades de HAPs que, em função da estabilidade da sua estrutura química e baixíssima solubilidade em água (a solubilidade em água do antraceno é de $0,076 \mathrm{mg} \mathrm{L}^{-1}$ ), não são degradados pela maioria dos microrganismos do solo (JOHNSEN et al., 2005). Além disso, esses compostos apresentam forte tendência de sorção às partículas orgânicas e minerais do solo, o que reduz sua biodisponibilidade aos microrganismos degradadores (JACQUES et al., 2007a).

A preocupação com a presença dos HAPs no ambiente deve-se as suas propriedades mutagênicas e carcinogênicas. Os HAPs são lipossolúveis e prontamente absorvidos no organismo dos mamíferos, onde seu metabolismo gera compostos epóxidos, que reagem com o DNA, podendo causar mutações e cânceres no pulmão, no intestino, no fígado, no pâncreas e na pele (CHAKRADEO et al., 1993; NETTO et al., 2000).

Uma alternativa para a remoção desses compostos do ambiente é pela biorremediação, em que os microrganismos degradadores irão transformá-los em substâncias inertes, $\mathrm{CO}_{2}$ e água (ALEXANDER, 1999). No entanto, a biorremediação pode ser limitada se as condições físicas e químicas do solo não forem favoráveis à sobrevivência e à atividade dos microrganismos degradadores (BARTHA, 1986; CHENG \& MULLA, 1999; CHEN et al., 2008).

A adequada disponibilidade de água no solo é considerada por HAIDER (1999) o fator ambiental mais crítico para a biodegradação, pois uma alta atividade microbiana somente ocorrerá se houver grande disponibilidade de água aos microrganismos. No entanto, um elevado teor de água no solo pode reduzir a disponibilidade de oxigênio aos microrganismos aeróbios, que são os principais responsáveis pela degradação dos poluentes orgânicos nos horizontes superficiais do solo (ASPRAY, 2008).

$\mathrm{O} \mathrm{pH}$ afeta diretamente a atividade dos microrganismos por meio dos efeitos dos íons $\mathrm{H}^{+}$na permeabilidade celular e na atividade enzimática, assim como, indiretamente, pela influência na disponibilidade de macro e micronutrientes e na solubilidade do alumínio e dos metais pesados, que podem ser tóxicos aos microrganismos (CALDWELL, 2000).

A adição de nutrientes ao solo contaminado visando suprir as demandas dos microrganismos degradadores é denominada de bioestimulação e pode resultar no aumento das taxas de degradação do contaminante no solo (ATAGANA et al., 2003). A relação C:N:P de 100:10:1 (em molar) ou 120:14:3 (em miligramas) tem sido normalmente recomendada (CHENG \& MULLA, 1999). No entanto, várias pesquisas que avaliaram os efeitos da adição de $\mathrm{N}$ e $\mathrm{P}$ ao solo demonstraram resultados muito conflitantes, indicando que essa relação pode não ser a mais adequada (ATAGANA et al., 2003; LEYS et al., 2005; LEE et al., 2007).

Outros nutrientes que podem influenciar a degradação dos HAPs no solo são o ferro e o enxofre. Esses elementos participam da estrutura das enzimas dioxigenases, são cofatores enzimáticos e protegem a célula dos radicais superóxidos (HARAYAMA, 1999). Dessa forma, a adição de ferro e enxofre ao solo poderia aumentar as taxas de degradação dos hidrocarbonetos (LIEBEG \& CUTRIGHT, 1999; SANTOS et al., 2008).

O objetivo do presente estudo foi avaliar a influência do $\mathrm{pH}$, da umidade e da disponibilidade de nitrogênio, de fósforo, de ferro e de enxofre na biorremediação de um solo contaminado com antraceno, que foi o HAP utilizado neste trabalho por apresentar menor toxicidade em relação aos demais e porque tem sido utilizado como modelo nos estudos da dinâmica desses compostos no ambiente.

\section{MATERIAL E MÉTODOS}

O solo utilizado em todos os experimentos pertence à Unidade de Mapeamento Itapoã (Argissolo Vermelho-Amarelo Distrófico arênico) e foi coletado na profundidade de $0-20 \mathrm{~cm}$, em uma área agrícola, sem histórico de recebimento de nenhum tipo de resíduo. A análise desse solo foi realizada conforme TEDESCO et al. (1995) e apresenta as seguintes características: $\mathrm{pH}$ $\left(\mathrm{H}_{2} \mathrm{O}\right)=4,7 ; \mathrm{P}_{\text {Melich- } 1}=4,1 \mathrm{mg} \mathrm{dm}^{-3} ; \mathrm{K}=20,0 \mathrm{mg} \mathrm{dm}^{-3}$; $\mathrm{Al}^{2+}=0,2 \mathrm{cmol}_{\mathrm{C}} \mathrm{dm}^{-3} ; \mathrm{Ca}^{2+}=0,4 \mathrm{cmol}_{\mathrm{c}} \mathrm{dm}^{-3} ; \mathrm{Mg}^{2+}=0,2 \mathrm{cmol}_{\mathrm{c}}$ $\mathrm{dm}^{-3} ; \mathrm{H}+\mathrm{Al}=1,6 \mathrm{cmol}_{\mathrm{c}} \mathrm{dm}^{-3} ; \mathrm{CTC}_{\mathrm{pH}}=2,2 \mathrm{cmol}_{\mathrm{c}} \mathrm{dm}^{-3}$; $\mathrm{V}=29 \%$; $\mathrm{m}=8,9 \%$; e $\mathrm{MO}=9,0 \mathrm{~g} \mathrm{~kg}^{-1}$, Argila=90, $\mathrm{g} \mathrm{kg}^{-1}$. O solo foi peneirado em malha de $2 \mathrm{~mm}$ e, para elevar o $\mathrm{pH}$ a 6,5, foram adicionados $\mathrm{CaCO}_{3}$ e $\mathrm{MgCO}_{3}$ na proporção de $3: 1$, sendo o solo incubado com umidade gravimétrica de $10 \%$ por 60 dias. Posteriormente, esse solo foi contaminado em laboratório com 500mg de antraceno por $\mathrm{kg}$ de solo, com uma solução concentrada desse HAP dissolvido em acetona (8,333 $\mathrm{mg} \mathrm{mL}^{-1}$ ), que foi adicionada a $50 \mathrm{~g}$ de solo no interior de frascos respirométricos. Esses frascos foram colocados em estufa por $3 \mathrm{~h}$, a $50^{\circ} \mathrm{C}$, para evaporação da acetona, e em seguida foram adicionados mais $50 \mathrm{~g}$ de solo, procedendo-se intensa mistura (JACQUES et al., 2008). O solo foi fertilizado com o equivalente a $100 \mathrm{~kg} \mathrm{ha}^{-1}$ de $\mathrm{N}, 50 \mathrm{~kg} \mathrm{ha}^{-1}$ de $\mathrm{P}$ e $63 \mathrm{~kg} \mathrm{ha}^{-1}$ de $\mathrm{K}$, na forma de soluções de $\mathrm{NH}_{4} \mathrm{NO}_{3}$ e $\mathrm{KH}_{2} \mathrm{PO}_{4}$, havendo 
variações nessas quantidades somente quando um desses nutrientes era adicionado ao solo nas doses especificadas nos testes descritos abaixo. O solo recebeu um inóculo composto por um consórcio microbiano que apresentou comprovada capacidade de degradar e mineralizar esse HAP no solo (JACQUES et al., 2007b). Esse consórcio é formado por seis bactérias, identificadas como Mycobacterium fortuitum, Bacillus cereus, Microbacterium sp., Gordonia polyisoprenivorans, Microbacteriaceae bacterium e Naphthalene-utilizing bacterium, e um fungo, o Fusarium oxysporum. Para formação do consórcio microbiano foi realizada a mistura desses sete microrganismos, em quantidades iguais de célula de cada um deles, quantificado por densidade ótica e/ ou massa seca de células. O solo recebeu um total de 2,0x10 $0^{8} \mathrm{UFC}^{-1}$ desse consórcio microbiano, por meio de uma suspensão de células em água esterilizada (KÄSTNER et al., 1998). Detalhes dos procedimentos de produção do inóculo e da análise respirométrica estão descritos em JACQUES et al. (2008).

A influência das diferentes condições físicas e químicas na mineralização do antraceno no solo foi avaliada em ensaios respirométricos individuais. $\mathrm{O}$ efeito da umidade do solo foi avaliado em um ensaio com sete tratamentos. Destes, seis foram inoculados com o consórcio microbiano, recebendo as seguintes umidades gravimétricas (Ug \%): 1,25; 2,5; 5,0; 7,5; 10,0 e 12,5. Um tratamento de controle da inoculação, com Ug de 10,0\%, não foi inoculado com o consórcio microbiano (e foi denominado SI - Sem Inoculação), contendo somente os microrganismos autóctones do solo. O ensaio consistiu de um delineamento inteiramente casualizado, com quatro repetições. Os frascos respirométricos foram incubados no laboratório, por 54 dias, no escuro e na temperatura ambiente.

A mineralização do antraceno no solo com diferentes $\mathrm{pH}$ foi avaliada em um ensaio respirométrico com oito tratamentos, que corresponderam aos seguintes pH: 4,5; 5,0; 5,5; 6,0; 6,5; 7,0; 7,5 e um tratamento controle da inoculação, com pH 6,5, sem inoculação (SI) do consórcio microbiano. Para obtenção desses $\mathrm{pH}$, o solo recebeu diferentes quantidades de $\mathrm{CaCO}_{3}$ e $\mathrm{MgCO}_{3}$ na proporção 3:1, na forma de reagente comercial, e foi incubado com umidade gravimétrica de $10 \%$ de Ug, por 60 dias. O ensaio consistiu de um delineamento inteiramente casualizado, com quatro repetições. Os frascos respirométricos foram incubados no laboratório, por 56 dias, no escuro e na temperatura ambiente.

O efeito do $\mathrm{N}$ na mineralização do antraceno no solo foi avaliado em um ensaio com seis tratamentos, utilizando as doses, em $\mathrm{kg} \mathrm{ha}^{-1}$, de 0, 50, 100, 200, 400 e um tratamento controle, com $50 \mathrm{~kg} \mathrm{ha}^{-1}$ de $\mathrm{N}$, sem inoculação (SI) do consórcio microbiano. Ao final do ensaio, o $\mathrm{N}$ mineral do solo $\left(\mathrm{NH}_{4}^{+}\right.$e $\left.\mathrm{NO}_{3}^{-}+\mathrm{NO}_{2}^{-}\right)$foi determinado pelo método de micro-Kjeldahl (TEDESCO et al., 1995). A condutividade elétrica foi determinada no solo pelo método do extrato de saturação na relação 1:5 (TEDESCO et al., 1995) e a força iônica foi calculada a partir da equação descrita por SPARKS (1995). O ensaio consistiu de um delineamento inteiramente casualizado, com quatro repetições. Os frascos respirométricos foram incubados no laboratório, por 62 dias, no escuro e na temperatura ambiente.

A mineralização do antraceno no solo com diferentes teores de $\mathrm{P}$ foi avaliada em um ensaio respirométrico com cinco tratamentos, que corresponderam às doses, em kg ha ${ }^{-1}$, de 0, 50, 100, 200 e um tratamento controle, com $50 \mathrm{~kg} \mathrm{ha}^{-1}$ de $\mathrm{P}$, sem inoculação (SI) do consórcio microbiano. As relações $\mathrm{C}_{\mathrm{HAP}}: \mathrm{N}$ e $\mathrm{C}_{\mathrm{HAP}}: \mathrm{P}$ foram calculadas dividindo-se a concentração de $\mathrm{C}$ adicionada ao solo na forma de antraceno (472 $\mathrm{mg} \mathrm{kg}^{-1}$ de $\mathrm{C}_{\mathrm{HAP}}$ ) pelo teor de $\mathrm{N}$ mineral ou pelo teor de fósforo do solo (LEYS et al., 2005). O ensaio consistiu de um delineamento inteiramente casualizado, com quatro repetições. Os frascos respirométricos foram incubados no laboratório, por 34 dias, no escuro e na temperatura ambiente.

O efeito do Fe na mineralização do antraceno no solo foi avaliado em um ensaio com cinco tratamentos, que equivaleram às doses, em $\mathrm{kg} \mathrm{ha}^{-1}$, de 0,15, 30, 60 e um tratamento controle da inoculação, com $60 \mathrm{~kg} \mathrm{ha}^{-1}$ de Fe, sem inoculação (SI) do consórcio microbiano. O Fe foi adicionado ao solo na forma de uma solução de $\mathrm{FeSO}_{4} \cdot 7 \mathrm{H}_{2} \mathrm{O}$. Em cada um dos tratamentos, o $\mathrm{Fe}$ amorfo do solo foi determinado conforme TEDESCO et al. (1995). O ensaio consistiu de um delineamento inteiramente casualizado, com quatro repetições. Os frascos respirométricos foram incubados no laboratório, por 50 dias, no escuro e na temperatura ambiente.

A mineralização do antraceno no solo com diferentes teores de S foi avaliada em um ensaio respirométrico com cinco tratamentos, que corresponderam às doses, em kg ha-1, de 0, 10, 20, 40 e um tratamento controle da inoculação, com $20 \mathrm{~kg} \mathrm{ha}^{-1}$ de S, sem inoculação (SI) do consórcio microbiano. O $\mathrm{S}$ foi adicionado ao solo na forma de uma solução de $\mathrm{K}_{2} \mathrm{SO}_{4}$. O S do solo de cada um dos tratamentos foi determinado conforme TEDESCO et al. (1995). O solo dos ensaios do $\mathrm{P}$, Fe e $\mathrm{S}$ receberam quantidades variáveis de $\mathrm{K}$ e $\mathrm{S}$ em razão da aplicação dos tratamentos. Para manter constantes as adições dos elementos que não estavam sendo avaliados, foram 
utilizadas soluções de $\mathrm{KCl}$ e $\mathrm{K}_{2} \mathrm{SO}_{4}$. Esse ensaio consistiu de um delineamento inteiramente casualizado, com quatro repetições. Os frascos respirométricos foram incubados no laboratório, por 48 dias, no escuro e na temperatura ambiente.

\section{RESULTADOS E DISCUSSÃO}

A microbiota autóctone do solo apresentou baixíssima capacidade de mineralizar o antraceno, conforme demonstrado nos tratamentos sem inoculação (SI) da figura 1. Por outro lado, a inoculação do consórcio microbiano ao solo resultou em aumento da produção de C-CO $\mathrm{CO}_{2}$ indicando que a biorremediação desse solo dependeu da introdução de microrganismos com capacidade de degradação do contaminante e demonstrando que a introdução de microrganismos específicos pode acelerar a taxa de decomposição de antraceno, como verificado por KÄSTNER et al. (1998), em que a inoculação do solo com bactérias degradadoras eliminou o antraceno do solo em uma taxa 10 vezes maior e em tempo sete vezes menor que a microbiota autóctone do solo.

Na figura 1, observa-se que, quanto maior a umidade gravimétrica do solo, maior foi a produção de $\mathrm{C}-\mathrm{CO}_{2}\left(\mathrm{R}^{2}\right.$ de 0,85 com significância de $1 \%$ de probabilidade), o que confirma a afirmação de HAIDER (1999), o qual destaca que populações microbianas do solo com intensa atividade de degradação de compostos orgânicos demandam grande quantidade de água para suprir suas necessidades metabólicas. BARTHA (1986) também observou que a maior atividade de biodegradação de hidrocarbonetos ocorreu no solo com maior umidade avaliada. Observase ainda que, no tratamento com maior umidade gravimétrica (12,5\%), não houve redução da atividade de mineralização do antraceno, indicando que o oxigênio não foi limitante a esses microrganismos degradadores, que são aeróbios. Provavelmente, se valores mais altos de umidade gravimétrica tivessem sido avaliados, a inibição da atividade de mineralização do antraceno no solo fosse observada.

Conforme indicam os resultados, a umidade do solo é fator de grande importância na biorremediação do solo, haja vista que as reduções relativamente pequenas da umidade resultaram em significativas reduções da atividade de biodegradação. Ao nosso conhecimento, o monitoramento da umidade do solo nos locais onde a biorremediação está em curso tem sido negligenciado em favor de fatores químicos, como adubações fosfatadas e nitrogenadas, o que representa um comprometimento da eficiência da biorremediação.

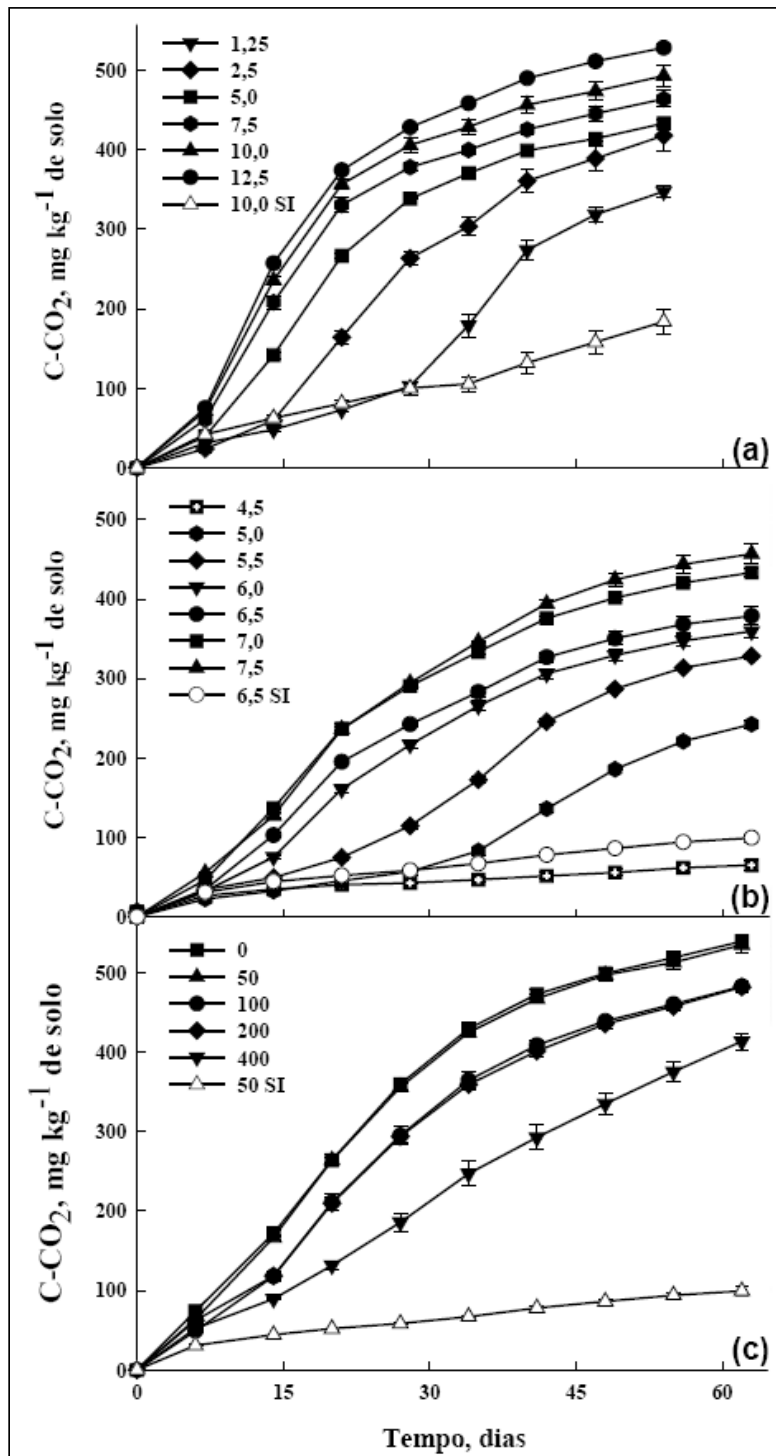

Figura 1 - Produção de $\mathrm{C}-\mathrm{CO}_{2}$ de um Argissolo arenoso contaminado com $500 \mathrm{mg}$ de antraceno $\mathrm{kg}^{-1}$ de solo, obtida a partir de três ensaios respirométricos em que se avaliou o efeito da umidade gravimétrica (\%) (a), do $\mathrm{pH}$ (b) e de doses de nitrogênio $\left(\mathrm{kg} \mathrm{ha}^{-1}\right)$ (c) na biorremediação desse solo. Um consórcio microbiano degradador de hidrocarbonetos aromáticos policíclicos foi inoculado ao solo, à exceção dos tratamentos sem inoculação (SI). Médias de quatro repetições; barras representam o desvio padrão.

Da mesma forma que a umidade, maior foi a mineralização do antraceno quanto maior o pH do solo (Figura 1) ( $\mathrm{R}^{2}$ de 0,86 com significância de 1\% de probabilidade), indicando ser este um fator ambiental a ser considerado na biorremediação do solo, apesar dos poucos estudos na literatura especializada. No $\mathrm{pH}$ natural do solo $(4,5)$ houve total inibição da 
mineralização do antraceno, mesmo sendo o solo fertilizado com N, P e K e inoculado com um consórcio microbiano que apresenta alta capacidade de mineralizar esse composto. As maiores produções de $\mathrm{C}-\mathrm{CO}_{2}$ nos tratamentos com pH 7,0 e 7,5 indicam que a atividade metabólica do consórcio é sensível à acidez do solo, o que pode ser consequência dos procedimentos de cultivo dos microrganismos em meios de cultura com $\mathrm{pH}$ 7,0, que pode ter selecionado um consórcio microbiano neutrofílico. ATAGANA et al. (2003) também observaram que as maiores contagens dos microrganismos degradadores e as maiores degradações dos hidrocarbonetos no solo ocorreram nos pH 6,5 e 7,0.

Verifica-se, na figura 1 , que, com o aumento da dose de $\mathrm{N}$, houve tendência de redução da mineralização do antraceno no solo. Após 62 dias, as maiores produções de C-CO foram quantificadas nos tratamentos de 0 e $50 \mathrm{~kg} \mathrm{ha}^{-1}$. A adição de 100 ou $200 \mathrm{~kg}$ ha ${ }^{-1}$ reduziu essa produção em $11 \%$ e em $26 \%$, na dose de $400 \mathrm{~kg} \mathrm{ha}^{-1}$, respectivamente. A inibição da degradação do HAP pela adição de nitrogênio também tem sido reportada por outros autores (JOHNSON \& SCOW, 1999; ASPRAY et al., 2008).

O aumento na concentração do nitrato em um biorreator eliminou completamente a degradação do antraceno por Mycobacterium, que, segundo LEYS et al. (2005), deveu-se ao incremento da força iônica da solução, que atingiu o elevado valor de 0,250. Em vista dessa possibilidade, calculou-se a força iônica nos solos que receberam diferentes doses de $\mathrm{N}$ (Tabela 1 ). Observa-se que o aumento da dose resultou no aumento da força iônica do solo, porém os valores foram muito inferiores ao nível inibitório anteriormente citado e semelhantes aos determinados por LEYS et al. (2005) em outros solos. Dessa forma, a força iônica não foi responsável pela inibição da mineralização do antraceno do solo.

Na tabela 1, observa-se a alta concentração de $\mathrm{N}$ mineral no solo que não recebeu adubação, provavelmente em razão da mineralização da matéria orgânica durante os procedimentos de preparo do solo e correção do pH. Com o aumento da dose de N, há tendência da redução da nitrificação. Na dose zero, todo o $\mathrm{N}$ mineral do solo encontrava-se na forma de $\mathrm{NO}_{3}^{-}+\mathrm{NO}_{2}^{-}$. Na dose de $50 \mathrm{~kg} \mathrm{ha}^{-1}, \mathrm{o} \mathrm{NH}_{4}^{+}$representava menos de $12 \%$ do $\mathrm{N}$ mineral do solo, enquanto que, na dose de $400 \mathrm{~kg} \mathrm{ha}^{-1}$, essa proporção aumentou para 35\%. CARMICHAEL \& PFAENDER (1997) observaram que as adições de $\mathrm{N}$ reduziram de 50 a $90 \%$ a mineralização do pireno em quatro solos, sendo esse comportamento observado somente quando o $\mathrm{NH}_{4}^{+}$e não o $\mathrm{NO}_{3}^{-}$era a fonte utilizada. Assim, a possibilidade de inibição da atividade de degradação do antraceno pelo $\mathrm{NH}^{+}$do solo pode ter ocorrido em vista da elevada quantidade desse cátion nas maiores doses avaliadas.

As relações $\mathrm{C}_{\mathrm{HAP}}-\mathrm{N}$ 120:12 e 120:17 não afetaram a mineralização do antraceno no solo, provavelmente por serem valores próximos ao recomendado na literatura de 120:14 (em miligramas) (CHENG \& MULLA, 1999). A redução dessas relações inibiu a atividade dos microrganismos degradadores (Figura 1 e Tabela 1), indicando que a relação 120:17 é o limite a partir do qual novas adições de $\mathrm{N}$ resultam em prejuízos ao processo de biorremediação.

A adição de $\mathrm{P}$ ao solo resultou em aumentos na disponibilidade desse nutriente, passando de 4,1mg $\mathrm{dm}^{-3}$, na dose 0 (teor natural do solo), para $88 \mathrm{mg} \mathrm{dm}^{-3}$, na dose $200 \mathrm{~kg} \mathrm{ha}^{-1}$. Porém, não resultou em aumentos significativos da produção de C-CO ${ }_{2}$, pois a diferença entre a dose 0 e a $200 \mathrm{~kg} \mathrm{ha}^{-1}$ foi de somente $5 \%$ (dados não apresentados), indicando que a disponibilidade do P não foi limitante à mineralização do antraceno. ATAGANA et al. (2003) também não observaram aumentos da degradação de vários HAPs no solo pela adição de $\mathrm{P}$. O consórcio microbiano mineralizou o antraceno em porcentagens muito semelhantes, mesmo estando submetido a relações $\mathrm{C}_{\mathrm{HAP}}: \mathrm{P}$ tão amplas quanto 120:1 (na dose 0) a 120:22 (na dose 200). As relações C:P 120:1 e 120:5 (na dose 50) se aproximaram do valor

Tabela 1 - Teor de amônio e nitrato+nitrito, força iônica e relação $\mathrm{C}_{\mathrm{HAp}}: \mathrm{N}^{1}$ no Argissolo arenoso com diferentes doses de nitrogênio, contaminado com 500mg de antraceno por quilo de solo e inoculado com um consórcio microbiano degradador de hidrocarbonetos aromáticos policíclicos. Médias de quatro repetições.

\begin{tabular}{|c|c|c|c|c|}
\hline Doses (kg ha $\left.{ }^{-1}\right)$ & $\mathrm{NH}_{4}^{+}\left(\mathrm{mg} \mathrm{kg}^{-1}\right)$ & $\mathrm{NO}_{3}^{-}+\mathrm{NO}_{2^{-}}\left(\mathrm{mg} \mathrm{kg}^{-1}\right)$ & Força Iônica (M) & $\mathrm{C}_{\mathrm{HAP}}: \mathrm{N}(\mathrm{mg})$ \\
\hline 0 & 0,0 & 48,2 & 0,0018 & $120: 12$ \\
\hline 50 & 7,5 & 58,5 & 0,0021 & $120: 17$ \\
\hline 100 & 17,4 & 66,7 & 0,0025 & 120:21 \\
\hline 200 & 33,5 & 83,0 & 0,0030 & $120: 30$ \\
\hline 400 & 57,0 & 107,5 & 0,0043 & $120: 42$ \\
\hline
\end{tabular}

${ }^{1}$ A relação $\mathrm{C}_{\mathrm{HAP}}$ : $\mathrm{N}$ foi calculada dividindo-se a concentração de $\mathrm{C}$ adicionada ao solo na forma de antraceno pelo teor de $\mathrm{N}$ mineral do solo, conforme LEYS et al. (2005). 
recomendado na literatura, que é de 120:3, e proporcionaram altas taxas de mineralização do antraceno no solo. $\mathrm{O}$ aumento do teor de $\mathrm{P}$ no solo e a consequente redução dessa relação não resultaram em inibição da mineralização, indicando que o $\mathrm{P}$, ao contrário do $\mathrm{N}$, não apresentou toxicidade aos microrganismos degradadores, comportamento também observado por outros autores (CARMICHAEL \& PFAENDER, 1997; LEYS et al., 2005).

As adições do Fe e $\mathrm{S}$ nas doses avaliadas não resultaram em aumentos da mineralização do antraceno pelo consórcio microbiano, indicando que não houve limitação desses elementos (dados não apresentados). Nesse solo, o teor natural de Fe amorfo foi quantificado em $0,2 \mathrm{~g} \mathrm{dm}^{-3}$, e a adição de $15 \mathrm{~kg} \mathrm{ha}^{-1}$ não aumentou esse valor. Porém, com a adição de 30 e $60 \mathrm{~kg} \mathrm{ha}^{-1}$, a quantidade de ferro amorfo foi elevado para $0,3 \mathrm{~g} \mathrm{dm}^{-3}$, indicando que houve aumento da disponibilidade do ferro no solo, sem, no entanto, resultar em aumentos da mineralização do antraceno. A ausência de resposta à adição desse elemento pode ser explicada pela baixa demanda, em termos quantitativos, uma vez que, em média, esse elemento representa somente $0,2 \%$ da massa seca da célula bacteriana (CALDWELL, 2000).

O teor natural de S do solo, de 3,4mg dm-3, considerado médio para a nutrição de plantas (COMISSÃO, 2004), foi suficiente para suprir a demanda da microbiota degradadora. As adições de 10, 20 e 40kg ha $^{-1}$ incrementaram o teor de S no solo para 10,0; 13,1 e $32,8 \mathrm{mg} \mathrm{dm}^{-3}$, respectivamente, sem resultar em maior produção de $\mathrm{C}-\mathrm{CO}_{2}$ no solo. Entre os nutrientes inorgânicos, o enxofre é o quarto mais absorvido, com participação média de $1 \%$ na composição química celular bacteriana (CALDWELL, 2000). Mesmo assim, não houve resposta à adição do $\mathrm{S}$, o que pode estar relacionado à mineralização da matéria orgânica durante os procedimentos de preparo do solo e incubação para correção do pH .

\section{CONCLUSÕES}

$\mathrm{Na}$ presença de microrganismos degradadores, solos com elevadas umidades e $\mathrm{pH}$ próximos à neutralidade proporcionam as condições mais adequadas para a biorremediação do antraceno. Os solos com altas concentrações de $\mathrm{N}$ mineral e, por consequência, baixas relações $\mathrm{C}_{\mathrm{HAP}}: \mathrm{N}$ reduzem a eficiência do processo de biorremediação. A biorremediação desse Argissolo contaminado com antraceno não é afetada pela presença de diferentes teores de $\mathrm{P}$, Fe e S, nem pela presença de amplas relações $\mathrm{C}_{\mathrm{HAP}}: \mathrm{P}$.

\section{AGRADECIMENTOS}

Ao Conselho Nacional de Desenvolvimento Científico e Tecnológico (CNPq ) e à Coodedenação de Aperfeiçoamento de Pessoal de Nível Superior (CAPES), pelo apoio financeiro.

\section{REFERÊNCIAS}

ALEXANDER, M. Biodegradation and bioremediation. 2.ed. New York: Academic, 1999. 453p.

ASPRAY, T. et al. Effect of nitrogen amendment on respiration and respiratory quotient (RQ) in three hydrocarbon contaminated soils of different type. Chemosphere, Oxford, v.72, n.6, p.947-995, 2008. Disponível em: <http:// www.sciencedirect.com/science?_ob=PublicationURL \&_tockey $=\% 23$ TOC $\% 235832 \% 232008 \% 23999279993$ \% 23691502 \% 23 F L A \% 23 \&_c di = 5832 \&_p u bType $=$ J\&_auth $=$ y\&_acct $=$ C000037899 \&_version $=1 \&$ _urlVersi o $\mathrm{n}=0$ \&_ u s e r i d $=687358 \&$ m d $5=85$ a f 0 e 99aacb4adbcd8dec1c7168ce83>. Acesso em: 22 nov. 2009. doi: 1016/j.chemosphere.2008.03.017.

ATAGANA, H.I. et al. Optimization of soil physical and chemical conditions for the bioremediation of creosotecontaminated soil. Biodegradation, Dordrecht, v.14, n.4, p.297-307, 2003. Disponível em: <http:// www.springerlink.com.w10050.dotlib.com.br/ content/ $\begin{array}{llllllllllllllll}\mathrm{p} & 3 & 6 & \mathrm{~h} & 9 & 7 & 3 & 0 & 7 & 3 & 5 & 6 & 3 & 0 & \mathrm{~h} & 7\end{array}$ ?p=47bfa6d0bca74dd583a55b02a2445f71\&pi=5>. Acesso em: 22 nov. 2009. doi: 10.1023/A:1024730722751.

BAMFORTH, S.; SINGLETON, I. Bioremediation of polycyclic aromatic hydrocarbons: current knowledge and future directions. Journal of Chemical Technology and Biotechnology, Sussex, v.80, n.7, p.723-736, 2005. Disponível em: <http://www3.interscience. wiley.com/ search/allsearch?mode=citation\&contextLink=blah\&issn=\%2810974660\%2C1935-1836\%2C1935-181X\%2C1935-0554\%2C1934$998 X \% 2 \mathrm{C} 1934-9971 \% 29 \&$ volume$=80 \&$ issue $=7 \&$ pages $=723>$. Acesso em: 22 nov. 2009. doi: 10.1002/jctb.1276.

BARTHA, R. Biotechnology of petroleum pollutant biodegradation. Microbial Ecology, New York, v.12, n.1, p.155-172, 1986.

CALDWELL, D.R. Microbial physiology and metabolism 2.ed. Belmont: Star, 2000. 403p.

CARMICHAEL, L.M.; PFAENDER, F.K. The effect of inorganic and organic supplements on the microbial degradation of phenanthrene and pyrene in soils. Biodegradation, Dordrecht, v.8, n.1, p.1-13, 1997. Disponível em: <http://www.springerlink.com.w10050.dotlib.com.br/ c o n t e n t / m x 4 a 1 e h h b n 91 / ?p=1331276910b3476e8975afc25a6bb8e6\&pi=75>. Acesso em: 22 nov. 2009. doi: 10.1023/A:1008258720649.

CHAKRADEO, P.P. et al. Effect of benzo(a)pireno and methyl(acetoxymethyl)nitrosamine on thymidine uptake and induction of aryl hydrocarbon hydroxylase activity in human fetal esophageal cells in culture. Cell Biology International, Amsterdan, v.17, n.7, p.671-676, 1993. Disponível em: <http:// www.sciencedirect.com/science?_ob=ArticleURL\&_udi=B6WCB45R789B-1S\&_user $=687358 \&$ \&_coverDate $=07 \% 2 \mathrm{~F} 3$ $1 \% 2 F 1993 \&$ \&doc $=5 \&$ fmt $=$ high\&_orig=browse\&_srch=docinfo ( \% 23 toc \% $236734 \% 231993 \% 23999829992$ 
\%23312606\%23FLT\%23display\%23Volume)\&_cdi=67 $34 \&$ \& ort $=$ d \&_d oc anchor $=\&_{-}$c ct $=21 \&$ _ a c ct $=$ C $000037899 \&$ \&_version $=1 \&$ \&_urlVersion $=0 \&$ \&_u serid $=687358 \& \mathrm{md} 5=3 \mathrm{e} 32 \mathrm{f} 6316060 \mathrm{f} 5 \mathrm{ba} 97 \mathrm{fb} 8 \mathrm{ef} 8 \mathrm{a} 06 \mathrm{ac} 4 \mathrm{c} 9>$. Acesso em: 22 nov. 2009. doi:10.1006/cbir.1993.1117.

CHEN, J. et al. Multi-factors on biodegradation kinetics of polycyclic aromatic hydrocarbons (PAHs) by Sphingomonas sp. a bacterial strain isolated from mangrove sediment. Marine Pollution Bulletin, Amsterdan, v.57, n.6-12, p.695-702, 2008. Disponível em: <http://www.sciencedirect.com/ science?_ob=ArticleURL\&_udi=B6V6N-4SBHFKF-4\&_user= 687358 \&_c over Date = $12 \% 2$ F $31 \% 2$ F 2008 \&_rdoc $=60 \&$ \& fmt $=$ high\&_orig =browse\&_srch $=$ doc info( $\% 23$ toc \%235819\%232008\%23999429993\% $23692400 \% 23$ F L A \% 23 display\%23 Volume) $\&_{\text {_cdi }}=5819 \&_{-}$sort $=$d\&_docanchor $=\&$ \&_ct $=85 \&$ _ a c ct $=$ C $000037899 \&$ _version $=1 \&$ \&_urlVersion $=0 \& \_$userid $=687358 \& m d 5=5 a 806$ ce299aa55e8f73d53f322fe6afe $>$. Acesso em: 22 nov. 2009 . doi: 10.1016/ j.marpolbul.2008.03.013.

CHENG, H.H.; MULLA, D.J. The soil environment. In: ADRIANO, D.C. et al. Bioremediation of contaminated soils. Madison : ASA/CSSA/SSSA, 1999. Cap 1, p.1-13.

COMISSÃO DE QUÍMICA E FERTILIDADE DO SOLO - RS/ SC. Manual de adubação e calagem para os Estados do Rio Grande do Sul e de Santa Catarina. 10.ed. Porto Alegre: SBCS - Núcleo Regional Sul/UFRGS, 2004. 400p.

HAIDER, K. Microbe-soil-organic contaminant interactions. In: ADRIANO, D.C. et al. Bioremediation of contaminated soils. Madison: ASA/CSSA/SSSA, 1999. Cap 3, p.33-51.

HARITASH, A.K.; KAUSHIK, C.P. Biodegradation aspects of polycyclic aromatic hydrocarbons (PAHs): a review. Journal of Hazardous Materials, Amsterdam, v.169, n.1-3, p.1-15, 2009. Disponível em: $<$ http://www.sciencedirect.com/science?_ob=ArticleURL\&_udi=B6TGF-

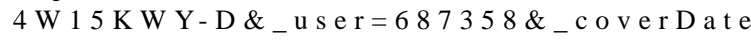
$=09 \% 2$ F $30 \% 2$ F $2009 \&_{-}$rdoc $=2 \&_{-}$f mt $=$high \& o r i g $=$ b r o w s e \& s r c h $=$ d o c info(\%23toc\%235253\%232009\%23998309998\%231283085\%23 F L A \% 23 dis p l a y \% 23 Volum e ) \& _ c di $=525$ $3 \&$ \& s or t $=$ d \&_d o c a n c h or $=\&_{\text {_ c t }}=169 \&$ \& c ct $=$ C $000037899 \&$ _version $=1 \&$ _url Version $=0$ \&_userid=687358\&md5=f97e95ac3550b2f20c70e05d6d391c92 >. Acesso em: 22 nov. 2009. doi: 10.1016/j.jhazmat.2009.03.137.

HARAYAMA, K. et al. Bacterial aromatic ring cleavage enzymes are classified into different gene families. Journal of Biological Chemistry, Stanford, v.264, n.26, p.1532815333, 1999. Disponível em: <http://intl.jbc.org/ search? author $1=\&$ fulltext $=\&$ pubdate_year $=1989 \&$ volume $=264 \&$ firstpage $=15328 \&$ submit $=$ yes. Acesso em: 22 nov. 2009.

JACQUES, R.J.S. et al. Biorremediação de hidrocarbonetos policíclicos aromáticos. Ciência Rural, Santa Maria, v.37, n.4, p.1192-1201, 2007a. Disponível em: <http://www.scielo.br/ s c i elo.php ? s c ript=s ci_art text \& pi d = S 0103 84782007000400049\&lng=en\& nrm=iso>. Acesso em: 22 nov. 2009. doi: 10.1590/S0103-84782007000400049.
JACQUES, R.J.S. et al. Characterization of a polycyclic aromatic hydrocarbon-degrading microbial consortium from a petrochemical sludge landfarming site. Bioremediation Journal, Philadelphia, v.11, n.1, p.1-11, 2007b. Disponível em: <http://web.ebscohost.com/ ehost/detail? vid=3\&hid=106\&sid=14d62cd6-6435-46b8-bc56f 050 a 6857 a 5 f \% 40 ses sionmgr 113 \& bdata $=$ J n N pd GU9ZWhvc3QtbGl2ZQ\%3d\%3d\#db=aph\&AN=24155880>. Acesso em: 22 nov. 2009. doi: 10.1080/10889860601185822.

JACQUES, R.J.S. et al. Microbial consortium bioaugmentation of a polycyclic aromatic hydrocarbons contaminated soil. Bioresource Technology, Dallas, v.99, n.7, p.2637-2643, 2008. Disponível em: $<$ http://www.sciencedirect.com/science?_ob=ArticleURL\&_udi=B6V244 N Y S H $76-4$ \&_u s e r $=687358$ \&_c overDat e $=05 \%$ 2F31\%2F2008\&_rdoc $=75 \&$ fmt=high\&_orig =browse\&_srch=doci n f o ( $\% 2 \begin{array}{llllllllllllllllll}\% & 2 & \text { t o c } & \% & 2 & 3 & 5 & 6 & 9 & 2 & \% & 2 & 3 & 2 & 0 & 0 & 8\end{array}$ \% $23999009992 \% 23680070 \% 23$ F L A \% 23 display\%23Volume) \&_cdi $=5692 \&$ \&_sort $=$ d \&_doc anchor $=\&_{\text {_ct }}=85 \&$ \&_a c ct $=$ C $000037899 \&$ \&_versi on $=1 \&$ \&_urlversion $=0 \&$ \& userid $=687358 \&$ md $5=$ 0962e0ffbd486c4ec532aa0c396810bc>. Acesso em: 22 nov. 2009. doi: 10.1016/j.biortech.2007.04.047.

JOHNSEN, A.R. et al. Principles of microbial PAH-degradation in soil. Environmental Pollution, Oxford, v.133, n.1, p.7184, 2005. Disponível em: <http://www.sciencedirect.com/ science?_ob=ArticleURL\&_udi=B6VB5-4CNGPBP-2\&_user= 687358 \& _ c o ve r D a t e = $01 \% 2$ F $31 \% 2 \mathrm{~F}$ 2005\&_rdoc $=12 \&$ \&mt $=$ high \&_orig $=$ browse \&_srch=docinfo(\%23toc\%235917\%232005\%23998669998\%23514773\%23F LA\%23display\%23Volume)\&_cdi=5917\&_sort=d\&_doca n c hor $=\&_{\text {_ c t }}=21 \&_{\text {_ a c c t }}=$ C $000037899 \&$ \& version $=1 \&$ \&urlVersion $=0 \&$ \&userid $=687358 \&$ md 5=5ca8a5490fad7016f0b83aa8b4338324>. Acesso em: 22 nov. 2009. doi: 10.1016/j.envpol.2004.04.015.

JOHNSON, C.R.; SCOW, K.M. Effect of nitrogen and phosphorus addition on phenanthrene biodegradation in four soils. Biodegradation, Dordrech, v.10, n.1, p.43-50, 1999. Disponível em: <http:// www.springerlink.com.w10050.dotlib.com.br/content/ r33j4g5631783338/?p=fc9a8c039886449b9eaa44466f8a0351\&pi=4>. Acesso em: 22 nov. 2009. doi: 10.1023/A:1008359606545.

KÄSTNER, M. et al. Impact of inoculation protocols, salinity, and $\mathrm{pH}$ on the degradation of polycyclic aromatic hydrocarbons (PAHs) and survival of PAHdegrading bacteria introduced into soil. Applied and Environmental Microbiology, Washington, v.64, n.1, p.359-362, 1998. Disponível em: <http:// a e m. a s m. org/c g i / r e p r i n t / 6 4/ $1 /$ 359 ? $\mathrm{maxt}$ os h o w $=\&$ H I T S $=10$ \& hit s $=10$ \& RESULTFORMAT $=\&$ fulltext $=$ PAH \& searchid $=1 \&$ FIRSTINDEX=0\&volume=64\&issue=1\&resourcetype=HWCIT $>$. Acesso em: 22 nov. 2009. doi: 10.1007/BF00172501.

LEE, S-H, et al. Degradation characteristics of waste lubricants under different nutrient conditions. Journal of Hazardous Materials, Amsterdan v.143, n.1-2, p.65-72, 2007. Disponível em: <http:// www.sciencedirect.com/science?_ob=ArticleURL\&_udi=B6TGF4KSRV52-6\&_user $=687358 \&$ \&coverDate $=05 \% 2$ F08\%2F200 $7 \&$ \&doc $=11 \&$ \& fmt $=$ high \&_orig =browse \&_srch $=$ doc info(\%23toc\%235253\%232007\%23998569998\%236496 62\%23FLA\%23display\%23Volume)\&_cdi=5253\&_sort=d\&_d ocanchor=\&_ct=91\&_acct $=C 000037899 \&$ \& version $=1 \&$ \&urlVersion $=0$ \&_userid=687358\&md5=4f51f7d1a269a724348e8ef0315ff909>. Acesso em: 22 nov. 2009. doi: 10.1016/j.jhazmat.2006.08.059. 
LEYS, N.M. et al. Influence of the carbon/nitrogen/phosphorus ratio on polycyclic aromatic hydrocarbon degradation by Mycobacterium and Sphingomonas in soil. Applied Microbiology and Biotechnology, New York, v.66, n. 6, p.726-736, 2005. Disponível em: <http://web.ebscohost.com/ ehost $/$ detail ?vid=4\&hid=101\&sid=4ce84168-c961-4392-a814a513d73e10e1\%40sessionmgr113\&bdata=JnNpdGU9 ZWhvc3QtbGl2ZQ\%3d\%3d\#db=aph\&AN=16243919> Acesso em: 22 nov. 2009. doi: 10.1007/s00253-004-1766-4.

LIEBEG, E.W.; CUTRIGHT, T.J. The investigation of enhanced bioremediation through the addition of macro and micro nutrients in a PAH contaminated soil. International Biodeterioration and Biodegradation, London, v.44, n.1, p.55-64, 1999. Disponível em: <http://www.sciencedirect.com/ science?_ob=ArticleURL\&_udi=B6VG6-3X9RYTF-9\&_user= 687358\& coverDate-07\%2F31\%2F1999\& idbc=9\& fint=high\& aig browse\& sdr-dbcin f o ( \% 23 t o c \% $236030 \% 231999 \% 23999559998 \%$ $23122789 \% 23$ FL A \% 23 display\%23 Volume)\&_cd $\mathrm{i}=6030$ \&_sort $=\mathrm{d} \&$ \&docanchor $=\&$ \& $\mathrm{ct}=11$ \&_acct $=\mathrm{C} 000037899 \&$ _version $=1 \&$ \&_urlVersion $=0 \&$ \&_userid $=687358 \& \mathrm{~m}$ d5=faea035ef23be557cd2bede4083e1446>. Acesso em: 22 nov. 2009. doi: doi:10.1016/S0964-8305(99)00060-8.

NETTO, A.D.P.et al. Evaluation of human contamination with polycyclic aromatic hydrocarbons (PAHS) and their nitrated derivatives (NHPAS): a review of methodology. Química Nova, São Paulo, v.23, n.6, p.765-773, 2000. Disponível em: <http://www.sbq.org.br/publicacoes/ quimicanova/qnol/2000/ vol23n6/index.html>. Acesso em: 22 nov. 2009. doi: 10.1590/ S0100-40422000000600010.

SANTOS, E.C. et al. Anthracene degradation and surfactant production by an iron induced Pseudomonas sp. Bioresource Technology, Dallas, v.99, n.7, p.2644-2649, 2008. Disponível em: <http:// www.sciencedirect.com/science?_ob=ArticleURL\&_udi=B6V244NYSH76-5\&_user $=687358 \&$ _coverDate $=05 \% 2$ F31 $\% 2$ F2008 \&_rdoc $=76 \&$ \& fmt $=$ high \&_orig=browse\&_srch=docinfo ( \%23 t oc \%235692\%232008\%23999009992\% $23680070 \% 23$ FL A $\% 23$ display $\% 23$ Volume)\&_cdi=56 $92 \&$ \&_sort $=$ d\&_d ocanchor $=\&$ \&_ct $=85 \&$ \&_acct $=$ C 00 $0037899 \&$ \& version $=1 \&$ \&urlVersion $=0$ \&_userid $=68735$ $8 \&$ md5=19988381626bab6cd4b0c179475cd182>. Acesso em: 22 nov. 2009. doi: 10.1016/j.biortech.2007.04.050.

SPARKS, D.L. Environmental soil chemistry. San Diego: Academic, 1995. 267p

TEDESCO, M.J. et al. Análises de solo, plantas e outros materiais. 2.ed. Porto Alegre: Departamento de Solos da UFRGS, 1995. 174p. 